\title{
More than one way to stop HCV
}

\section{By Tracey Baas, Senior Editor}

A French team led by Epixis S.A. has developed an HCV vaccine that triggers both a $\mathrm{T}$ cell response and broadly neutralizing antibodies in macaques. ${ }^{1}$ Because of the ability to elicit both types of immune responses, the vaccine could have advantages over other HCV vac-

cines in development

"This study represents a significant breakthrough in the field and offers much encouragement for the of an HCV vaccine in the future."

- Michael Houghton, University of Alberta successful development

that focus only on $\mathrm{T}$ cell responses or that elicit neutralizing antibodies that do not attack the multiple genotypes of HCV.

Six companies have $\mathrm{HCV}$ vaccines in early stage clinical trials (see Table 1, “HCV vaccines in clinical development").

$\mathrm{HCV}$ is difficult to neutralize because there are at least six distinct genotypes with more than 50 known subtypes. Genotypes 1a, 1b, 2b and $3 \mathrm{a}$ are the most common in the U.S., but even in a single infected individual, the virus is not homogeneous.

Epixis' vaccine has three components based on HCV genotype 1a: an adenovirus vector that produces HCV envelope protein E1 (E1) and E2, which elicit $\mathrm{T}$ cell responses, and two virus-like particles (VLPs) that present those proteins to the immune system and trigger antibody responses (see Figure 1, "Virus-like particles for $\mathrm{HCV}$ vaccine regimen").

The company first immunized macaques with the adenovirus vector to prime the immune system, followed by a boost with the two VLPs. This regimen provided $\mathrm{T}$ cell responses and antibody production against both HCV envelope proteins.

Next they showed cross-neutralization activity of the antibodies by using two types of in vitro assays based either on HCV pseudoparticles or cell culture-adapted HCV. Whereas HCV pseudoparticles mimic the early infection steps of HCV, making them useful for evaluating antibodies that neutralize virus entry, cell culture-adapted $\mathrm{HCV}$ goes through all stages of the virus' life cycle, allowing the evaluation of which life cycle stages are affected by the antibodies.

With the nonreplicating HCV pseudoparticles, sera from macaques showed 50\%-70\% neutralization toward the genotype 1a strain of HCV. Importantly, the vaccine also showed $10 \%-65 \%$ neutralization of 5 other genotypes of $\mathrm{HCV}$.

With a cell culture-adapted HCV, the team showed that the macaque sera had $>80 \%$ cross-neutralization against a non-type la strain of HCV.

Data were published in Science Translational Medicine.

The team included researchers from the University of Lyon, the French Alternative Energies and Atomic Energy Commission (CEA), Pierre and Marie Curie University, Centre National de la Recherche Scientifique (CNRS), Institut National de la Santé et de la Recherche Médicale (INSERM), the Pasteur Institute and PitiéSalpêtrière Hospital.

"Our work shows the prime-boost regime is effective in neutralizing HCV," said Charlotte Dalba, CEO of Epixis and co-corresponding author on the paper. "It also suggests that theoretically the strategy could be applied to any enveloped virus. The VLP can be redesigned to present the envelope proteins of your virus of interest rather than the envelope proteins of HCV."

"Historically, the HCV field in general has predicted that vaccines would only elicit genotype-specific neutralizing antibodies," said Michael Houghton, a virologist at the University of Alberta. "We now know that this is not the case, and as such, this study represents a significant breakthrough in the field and offers much encouragement for the successful development of an HCV vaccine in the future."

Houghton co-discovered HCV in 1989 and later developed an

Gag protein from MLV

Envelope protein(s) from HCV

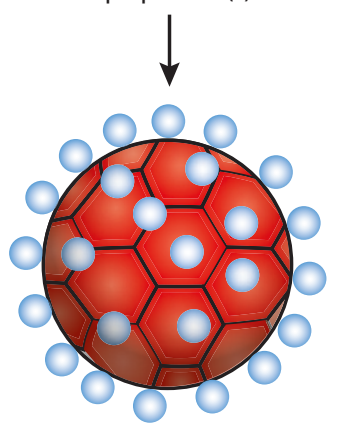

Figure 1. Virus-like particles for HCV vaccine regimen. The viruslike particle (VLP) is made up of multiple copies of gag protein from the Moloney murine leukemia virus (MLV) and envelope proteins from HCV. Gag self-assembles into a shell, resembling the conformation of native virus, and incorporates and displays HCV envelope protein E1 (E1) and E2 at the surface.

In their vaccine regimen, Garrone et al. incorporated a double boost step, using VLP-E1E2, which displayed genotype 1a E1 and E2, and VLP-E1G, which displayed a recombinant form of genotype 1a E1. 
Table 1. HCV vaccines in clinical development.

\begin{tabular}{lll}
\hline Company & Product & Description \\
\hline $\begin{array}{l}\text { Chrontech Pharma AB } \\
\text { (SSE:CTEC) }\end{array}$ & ChronVac-C & $\begin{array}{l}\text { DNA vaccine against HCV delivered using the Medpulser electroporation platform } \\
\text { from Inovio Pharmaceuticals Inc. (NYSE-A:INO) }\end{array}$ \\
\hline $\begin{array}{l}\text { GlobeImmune Inc. } \\
\begin{array}{l}\text { Intercell AG } \\
\text { (VSE:ICLL; OTCQX:INRLY) }\end{array}\end{array}$ & $\begin{array}{l}\text { Tarmogen immunotherapy } \\
\text { (GI-5005) }\end{array}$ & $\begin{array}{l}\text { Whole, heat-killed, recombinant Saccharomyces cerevisiae yeast engineered to express a } \\
\text { fusion protein of HCV non-structural protein 3 (NS3) and HCV core protein }\end{array}$ \\
\hline $\begin{array}{l}\text { Transgene S.A. } \\
\text { (Euronext:TNG) }\end{array}$ & MVA-HCV (TG4040) & $\begin{array}{l}\text { Vaccine containing five HCV peptides and poly-L-arginiene } \\
\text { encoding immunogenic NS3, NS4 and NS5B }\end{array}$ \\
\hline $\begin{array}{l}\text { Okairos AG } \\
\text { HCV vaccine }\end{array}$ & $\begin{array}{l}\text { Vaccine composed of two non-cross-reacting, replication-defective adenovirus vectors Phase I } \\
\text { (chimpanzee-derived serotype 3 (AdCh3) and the rare human serotype 6 (Ad6)) that } \\
\text { encode NS3, NS4 and NS5 }\end{array}$ \\
\hline
\end{tabular}

${ }^{\mathrm{A} C h r o n t e c h}$ and Transgene are combining their products in a Phase I trial. ${ }^{~}$ Intercell is testing its vaccine with the small molecule nitazoxanide from Romark Laboratories L.C. in a Phase II trial.

HCV E1E2 vaccine candidate when he worked at Chiron Corp. (now part of Novartis AG).

Novartis had planned to run a Phase II trial to assess the vaccine's protective efficacy, but Houghton told SciBX that work faltered

\section{"The adenovirus priming} vector used in our studies could be replaced by any of the $\mathrm{HCV}$ vaccine candidates being developed by our competitors that induce $\mathrm{T}$ cell responses. That would make those companies potential collaborators rather than competitors."

-Charlotte Dalba, Epixis S.A. after his departure in 2007 and development was suspended due to financial and other considerations. $^{2}$

\section{Staying neutral(izing)}

A major limitation to the study was the modest amount of crossneutralization of other viral types that were not genotype $1 \mathrm{a}$.

Houghton wanted to see more evidence for cross-neutralization. "Although Dalba's team has shown strong antibody cross-neutralization against one type of cell culture-adapted HCV, chimeric cell culture-adapted HCVs expressing envelope proteins from seven major genotypes of $\mathrm{HCV}$ are now available. ${ }^{3}$ It would be appropriate to show that the prime-boost regimen elicits neutralizing antibodies against the seven chimeric HCVs."

"We think that, together, the two types of in vitro assays usedbased either on HCV pseudoparticles or cell culture-adapted HCVprovide ample evidence for heterologous cross-neutralization," said Dalba. "However, the chimeric cell culture-adapted HCV to further test for cross-neutralization could be an interesting, although not indispensable, addition."

Animal models for possible challenge studies include chimpanzees, severe combined immuno-deficiency (SCID) mice with humanized chimeric livers and a newly developed immune competent mouse model. ${ }^{4}$

"If they do test efficacy in chimpanzees, the efficacy should be obtained using a priming vector that is applicable for use in man," suggested Houghton. "Most humans have been exposed to the adenovirus that Epixis used as the priming vector, so I think they need to select a vector that does not have herd immunity for clinical testing."

Most children have had mild infections with adenovirus by the time they start school. If patients have pre-existing antibodies to adenovirus, the immune system will fight the adenovirus vector and the vector will not be able to generate the HCV envelope proteins.

"The adenovirus priming vector used in our studies could be replaced by any of the HCV vaccine candidates being developed by our competitors that induce T cell responses," said Dalba. "That would make those companies potential collaborators rather than competitors."

Epixis said it has no plans for challenge studies at this time and its next steps are toxicology studies and clinical studies. Dalba said the company has been acquired by an undisclosed U.S. drug developer. "They will make that information public by the beginning of September," she said.

The HCV prime-boost regimen is patented and licensed by Epixis.

Baas, T. SciBX 4(33); doi:10.1038/scibx.2011.924

Published online Aug. 25, 2011

\section{REFERENCES}

1. Garrone, P. et al. Sci. Transl. Med.; published online Aug. 3, 2011; doi:10.1126/scitranslmed.3002330

Contact: David Klatzmann, Pierre and Marie Curie University, Paris, France

e-mail: david.klatzmann@upmc.fr

Contact: Charlotte Dalba, Epixis S.A., Lyon, France

e-mail: cd@epixis.com

2. Eisenstein, M. Nature 474, S16-S17 (2011)

3. Gottwein, J.M. et al. Hepatology 49, 364-377 (2009)

4. Baas, T. SciBX 4(24); doi:10.1038/scibx.2011.675

COMPANIES AND INSTITUTIONS MENTIONED

Centre National de la Recherche Scientifique, Paris, France

Epixis S.A., Paris, France

French Alternative Energies and Atomic Energy Commission,

Fontenay aux Roses, France

Institut National de la Santé et de la Recherche Médicale, Paris, France

Novartis AG (NYSE:NVS; SIX:NOVN), Basel, Switzerland

Pasteur Institute, Paris, France

Pierre and Marie Curie University, Paris, France

Pitié-Salpêtrière Hospital, Paris, France

University of Alberta, Edmonton, Alberta, Canada

University of Lyon, Lyon, France 